\title{
A Socio-pragmatic Perspective of Spanish and Persian Greeting
}

\author{
Ali Elhami \\ Universidad Autónoma de Madrid (UAM), Madrid, Spain
}

\begin{abstract}
Due to an increasing number of migration of Iranians to Spain and language and cultural problems they might face in the new society, a model of socio-pragmatic contrastive analysis was used with the intention of comparing the Spanish and Persian verbal and nonverbal greeting forms with the aim of helping Iranian immigrant in Spain for having a better understanding of cultural differences in greeting forms. In this study, the naturalistic context was used for both Spanish and Persian forms of greeting. This study shows two Spanish and two Persian patterns for greetings to show the differences and similarities between Persian and Spanish greeting to be a help for Iranian immigrants who are newcomers in Spain to be able to adapt themselves to Spanish culture which greeting is a part of it.
\end{abstract}

Index Terms - Socio-pragmatics, Immigration, Speech act, Greetings forms, Cross-cultural, Contrastive linguistics

\section{INTRODUCTION}

True communication engenders better cross-cultural understanding and relationships. People in different countries, based on their cultural traditions and language, communicate differently which this dissimilarity can give rise to misunderstanding and also sociopragmatic failure. The goal of this study is to ferret out the fact about verbal and nonverbal differences between Madrilenian Spanish (MS) and Tehrani Persian (TP) forms of greeting. Also to find out if the greeting (verbal and non-verbal) behaviors change in different relationships to facilitate the acculturation process of Iranian immigrants in Spain and also to improve the sociopragmatic knowledge of Iranians in Spain in the context of greeting as well as avoiding cross-cultural pragmatic failure. In this essay, a socio-pragmatic approach will be used to reveal the dissimilarities of Persian and Spanish greeting behaviors.

\section{BACKGROUND OF THE STUDY}

Migration is a decision people of different ages make to change their lives for finding better job opportunities, having an easier life, or studying in universities around the world, and many other reasons. During this way, they face many problems such as racism, understanding cultural differences, and going to the target country's social gathering (Elhami, 2020a). But they may be able to lessen those types of difficulties by learning sociopragmatic knowledge, which the first and the most important one in every communication is greeting (verbally and non-verbally).

Here it is essential to consider the definition of sociopragmatic which is an important area in cross-cultural contact. Sociopragmatics could be defined as the use of language in a social situation (Nodoushan, 2007) or in another word it studies the relationship between social context and discourse (Holmes and King, 2017), for example, friends (same-sex and different-sex), family members or people who see each other for the first time use distinct forms of greeting, in different societies. Also, the way of communication may change in different situations, for instance, the way of greeting between a father and a son or a couple in a formal setting might be different from the way they greet in an informal setting. Here this shows a need to be explicit about exactly what is meant by the word "situation", based on Nodoushan (2007) situation is a setting that communication takes place.

As this paper is a sociopragmatic study we need to focus on linguistic and sociological categories. Sociopragmatic is connected to the notion "Speech act", hence, we need to take the "speech act" which first invented by Austin (1962) into consideration. The speech act is defined as different ways to convey a message (Searle, 1977; Ibrahim, 1995). In fact in speech act communicators express two kinds of meaning, propositional and illocutionary meaning. The former is the normal and basic meaning of the utterance, for example, give me a glass of water, whereas the illocutionary meaning that is a deeper meaning of the sentence, for example, I am thirsty, in this situation the speaker wants the hearer to receive the meaning and give him/her something to drink.

Nodoushan (2007) defines conversation as using different types of speech acts. Speech act can be classified into five categorizations which are commissive, declarative, directive, expressive, and representative (Searle, 1977). The first one (commissive) which is a type of treat or promise means to commit the listener to doing something. For example, I will buy you a gift tomorrow (promise) or I will buy you a gift tomorrow if you do your homework well (treat), this type (treat) could be seen between parents and children, teachers and students, and generally, it is used to motivate someone. The second one (declarative) is another type of speech act that makes a great change, such as you are a mother now, you 
passed your exam, you are accepted in Harvard University, or even it can be in a negative form, you lost your child, or you are not allowed to leave the country. Speech act that makes the listener do something can be seen in imperative statements such as go out, come in, eat your food, do this, or in form of negative, such as do not eat this food or do not wear these shoes. However, expressive speech act which is about conveying the feeling such as love, hate, apology, or thanking someone, the examples of this type are, I love you, I hate this food, thank you for letting me in, etc. And the last one, representative speech act, which is about describing an event or reporting something, for instance, this is a Persian tradition, or a Spanish omelet, or an Italian pizza. Representative speech act can be observed among migrants and the target group in abundance. Generally speaking, majority and minority groups are keen on introducing their traditions and aspects of cultures to each other, for instance, eating habits, greeting forms, dress code, etc. spending time in a cafeteria is a Spanish habit, this is Spanish Churros, this is Spanish food, this drink is Spanish, are those many immigrants in Spain might hear from a native speaker.

The conversation usually shapes with the greeting of the utterances. Indeed, greeting is a key to start up social interaction. Sacks (1975) implies two main characteristics of greeting, which firstly happens at the first of conversation, and secondly, all speakers participate in this part of the conversation. In greeting forms age, gender, context, relationships, etc. matter, for example, teenagers might have a different form of greeting from elderly people (in the same society), or males might have different forms form females. Concerning gender, in a study about greeting forms among male and female Persian speakers by Dezhhara, Rezaei, Davoudi, \& Soltani Kafrani (2012) found that there is a significant difference between male and female greeting form, they observe that men are more informal whereas women show more feeling toward each other in a friendly conversation. Context is another important point that might have an effect on types of conversation and the formality or informality of the sentences people use, for instance, a conversation between two friends in an academic context might be different with the same conversation in a park, in short, people in different contexts might have different types of greeting with the same interlocutor. Another important factor which was mention above is the relationship, which could force or motivate people to use more formal or less formal vocabularies while greeting or conversing, relatedly in a study about greeting forms, Krivonos and Knapp (1975) found that greeting verbal and nonverbal behavior varies in accordance with the relationship between interlocutors. For instance, a wife and a husband, mother and daughter, teacher and student, two friends, and seller and customer all have different forms of greeting.

Time in greeting is an issued that we need to take it into account, which sometimes becomes complicated for immigrants, for instance in Iran at about 12 (noon) people use "Zohr be kheir" which in the USA or other English language countries "good noon" seems meaningless to the English native speakers, and those Persians, with a lower level of language, who use word for word translation to communicate might face problems. In point of view of Halliday (1979), the greeting is classified as time-free and time-bound. "Hola" in Spanish and "Salaam" (Hello) in Persian or “,cómo estás?” in Spanish and "chetori?” (How are you?) in Persian are examples of the time-free form of greeting, which can be used in any time of the day or year, in contrast, the time-bound form of greeting can be daily and seasonal, and time plays an important role in using them, for example, "Buenos días" in Spanish and "sobh bekheir" (Good morning) in Persian are examples of daily time-bound and "sale no mobarak" in Persian and "Feliz año nuevo" (Happy new year) in Spanish are examples of seasonal time-bound greeting, this is important to mention people do not use greeting in all contexts, there are some situations that conversation does not start with greeting (Coulthard, 1985) for instance asking a direction, or time on the street.

Another aspect of starting up a conversation which should be taken into consideration is introducing someone to another. In this situation culture plays a very important role, for example in Persian culture, people use title and also the last name for introducing someone whereas in Spanish culture people usually use the first name without a title.

There is an example of a very short conversation between 3 Persians:

Parviz: "aghaye salaami, ishoun mohandes kamali hastand"

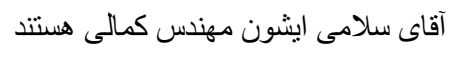

(a:qa:-ye Salami Ifu:n mo:hændes Kamali hæstænd)

Mr. Salaami, this is engineer Kamali.

Hasan Salami: "mohandes Kamali as molaghate shoma khoshbakhtam"

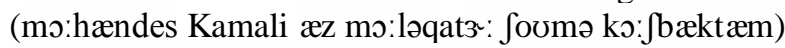

Engineer Kamali nice to meet you.

Javad Kamali: “Man ham as molaghate shoma khoshbakhtam aghaye doctor” من هم از ملاقات شما خوشبختم آقاى دكتر

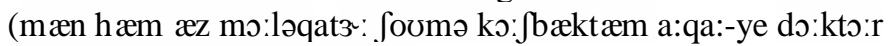

Nice to meet you Mr. Doctor

As the above example shows, in the Persian language two titles or a title and a job usually come together in formal situations such as Mr. Doctor, Ms. Engineer, Mr. Professor, or Mrs. Teacher, to show more respect to the interlocutor or/and the listener, what is noteworthy is that not using the title in the workplace, such as school, university, or company, especially between professor and student(s), professor and professor, teacher and students(s), teacher and teacher, manager and employee(s) is considered impolite. Indeed jobs with a higher social position such as engineer, doctor, and lawyer are considered title which should be used with another title such as Mr., or Ms.in formal contexts. Using these jobs only as a title is considered rude and used humorously, for instance, when calling someone an engineer means he/she is not clever or done something wrong. 


\section{Statement OF THE STUdy PuRPose}

Iranians, like many other nationalities, prefer English language countries, such as the UK, the USA, Australia, and Canada, for migration, due to different reasons that one of the most important ones is decreasing their linguistic problems they might face in a new society. However, due to difficulties for immigrating to those counties such as the long process of receiving Visa and financial issues (as the cost of living in those countries is expensive), Spain is another destination for those groups of Iranians who are seeking for good weather, lower cost of living, and faster visa process (Elhami, 2020b). Since immigration to Spain does not require any language certificate, those who immigrate to Spain might face more problems than those who chose English language countries as their destination. As mentioned, Iranians move to Spain to work, live and/or study not only might face language problems, but they may face cultural differences in many aspects which one of them is greeting in Spain.

The main purpose of this paper is firstly for both Iranians and Spaniards to understand each other's greeting behaviors, and secondly for Iranians who want to adapt themselves to the Spanish culture and to initiate a better and more successful type of conversation (face to face, on the phone, formal, and informal). Addressing people, which is using a title for people, or using first name or last name plays a very notable role in greeting. For example in a face to face interaction in Iran using a title is a must in most of the places even between friends or couples, for example, at the workplace, or formal gatherings a wife and a husband use title while talking to each other to show respect, and using the first name in the workplace (e.g., hospital, school, university, company, and bank) is considered impolite and is not recommended, in contrast, using the title in Spain is not very common, and titles normally are used for elderlies. These differences between Persian and Spanish culture in using title can lead to a misunderstanding between communicators.

Different types of articles have been written about different behaviors in greeting in different cultures such as English and Arabic greeting (Al-Khafaji, 2009; Almegren, 2018). And many studies between English and Persian language and culture (Nodoushan, 2007; Farsi \& Zarei, 2013; and Moradi \& Chen, 2018), however, with the increasing tendency among those Iranians who plan to leave their country and chose Spain as their destination there is a need for studying and informing newcomers (Persian) about Spanish greeting form. Hence, this study is going to find the verbal and nonverbal differences of greeting between Persians and Spaniards in different situations. In the following part of this article, different forms of Persian and Spanish greetings in different situations will be presented.

\section{THE DATA}

In this study, we focused on 552 time-free and time-bound greeting behavior of Iranians in Tehran in different situations between middle-class people and different genders, and also 453 greeting behavior of Spaniards in Madrid between middle-class people and different genders from Madrid.

\section{A. Persian Greeting Forms}

While talking to people from different societies, and cultural backgrounds, we might face different ways of speech act and greeting forms. For example in Iran (Tehran), people with different social-class, age groups, genders, education levels, and jobs, communicate differently. One should bear in mind that it is not possible to generalize the forms of greetings (verbal and nonverbal) for both Persians and Spaniards. Persian greeting form could be divided into two timefree and time-bound categories.

Following are some examples of time-free and time-bound greeting in Persian:

Time-free greeting examples:

1. sæ'la:m (?æ'leikəm) [Hello/Hi] سلام

2. ?æ'leikəm-ə-sæ'la:m [Hello/Hi] (Said by the hearer in return) عليك سلام

3. (?æz mo'la:qa:t ba: shomaa/mo'la:qa:t-e-sho'ma:) xoshbæxt-æm. [Glad to meet you] از ملاقات شماملاقات با خوشبختم

4. (?æz didæne shomaa/mo'la:qa:t-e-sho'ma:) xoshbæxt-æm. [Nice to see you] از ديدن شما /ملاقات شما خوشخيخ

5. ha:l-e ta:n/sho'ma: che'tore? [How are you?] (plural you) حال شما جطور

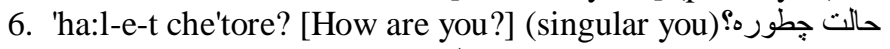

7. che'tori? [Are you OK?] جطورى

Time-bound greeting (daily and seasonal) examples:

1. Sobhe sho'ma: be'xeir. [Good morning] (Daily, more formal) صبح شما بخير

2. Sobh be'xeir. [Good morning] (Daily, less formal) صبح بخير

3. Shæbe sho'ma: be'xeir. [Good night] (Daily, more formal) شب شما بخير

4. Shæb be'xeir. [Good night] (Daily, less formal) شب بخير

5. Ru:ze sho'ma: be'xeir. [Good day] (Daily, more formal)روزشما بخير (Dوز

6. Ru:z be'xeir. [Good day] (Daily, less formal) روز بخير foul)

7. Tævælode sho'ma moba:'ræk. [Happy birthday to you.] (Seasonal, formal) تولد شما مباركاركا

8. Tævælodæt moba:'ræk. [Happy birthday to you.] (Seasonal, less formal) تولدت مباركارك

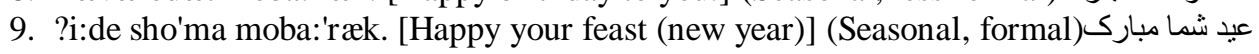

10. ?i:d-æt moba:'ræk. [Happy your feast (new year)] (Seasonal, less formal) عيدت مبارك

In Iran, the common form of greeting when people see each other is "sæ'la:m." (HELLO), which is used in both formal and informal contexts. In more formal contexts both "sæ'la:m." which is time-free and a time-bound form may 
be used such as "sæ'la:m Ru:z be'xeir. " (Hello, good day) or sæ'la:m Sobh be'xeir (Hello, good morning). The interesting point about Iranian greeting form is that generally they use Sobh be'xeir. [Good morning] when they get up in the morning and Shæb be'xeir. [Good night] when they want to go to bed at night.

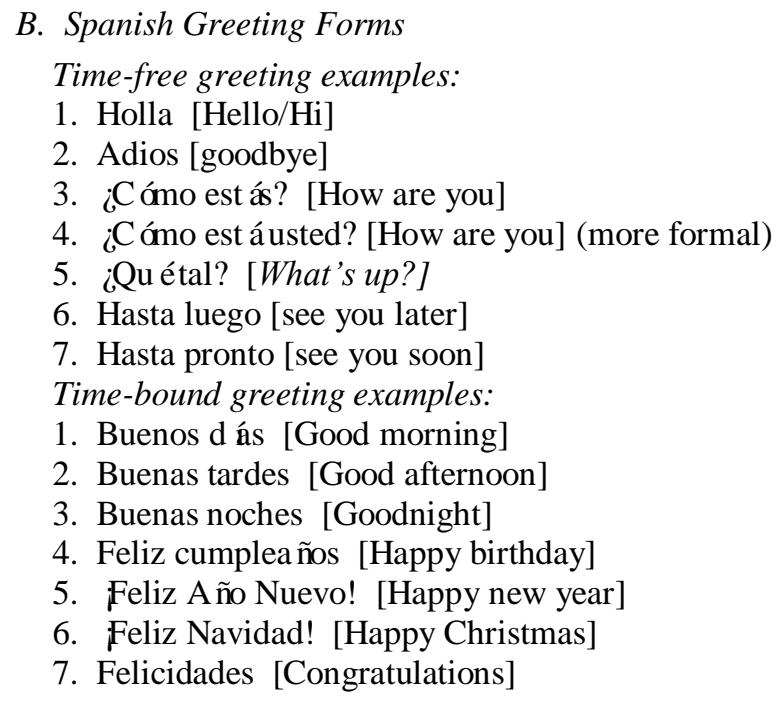

\section{RESUlT AND DisCUSSION}

Observations in this study show that Spanish greeting form the same as English greeting form lacks "“"zohr-e sho'ma:be'xeir" which means (good noon). Likewise, in Persian "Sobh be'xeir", "Shæb be'xeir", "Ru:z be'xeir", etc. generally used in more formal situations and sæ'la:m [Hello/Hi] is used in all situations whereas in Spanish which those are used in daily greeting form. "Sobh be'xeir" in Persian is used to greet after waking up in the morning and "Shæb be'xeir" is used to greet before going to bed and sometimes means goodbye (at night). Greeting form among Persians normally starts by shaking hands (girl/girl. Boy/boy, and for less religious families, girl/boy), whereas Spanish form which starts with two kisses (normally girl/girl, or boy/girl), that this cultural difference makes a complex situation for Iranian immigrants in first days of their entrance, also for those religious people it might seem disrespect towards Spaniards who are not familiar with Islamic religion and Persian culture. In Persian, using a title is a very important part of communication behavior and must be used at the workplace, street, and family for elderly people, while in Spain title is mostly used for elderly people to show respect.

In observations, I saw Iranians try to be more formal in the workplace and academic environments (e.g., universities, language schools, and schools) and they never use the first name in the workplace such as a bank, and office that may consider rude and impolite, while in Spain using the first name is not considered rude or disrespectful. Another important greeting behavior which is different among Persians and Spaniards is related to the nonverbal greeting. In Iran, standing up when someone enters a place is a sign of high respect. Some examples for this situation are, when grandparents(s) enter to the room younger generations should stand up for them, when a teacher or professor enters his/her class students must stand up for them when a boss comes to a place others stand up for them when guest(s) enter to the home the host and other guests who came before them stand up, and this form of greeting (nonverbal) normally happens before the verbal greeting.

\section{A. Example One}

\section{Persian:}

This conversation happened in Iran in a bank between a banker and a customer.

Banker: sæ'la:m, che'tor mi:tu:næm kəumæketu:n kəonæm?

(Hello, how can I help you?)

Customer: sæ'la:m, mi:kha:sta:m hesıb bırım bız ko:ni:d.

(I wanted you to open an account for me)

\section{Spanish:}

The same situation in Spain

Banker: buenos días. ¿en qué le puedo ayudar?

(Good morning, how can I help you?)

Customer: Buenos días. Me gustaría abrir una cuenta, por favor.

(Good morning, I would like to open a bank account please.)

In examples above we see both Iranian banker and customer used the plural form in the verbs during the conversation, (kəumæket (help you) [singular form of the second person] kəumæketu:n (Help you) [plural form of the second person] and ko:ni: (you do) [singular form of the second person] ko:ni:d (you do) [plural form of the second person] to show 
respect, whereas Spanish one in which both interlocutors show their respect by the intonation they use and also by "por favor" (please), and the banker uses "Le" in the sentence. ¿en qué le puedo ayudar? instead of "Te" to show respect to the customer.

\section{B. Example Two}

Persian:

This conversation happened between two friends (boys) who met each other on the street.

Reza: sæ'la:m, che'tor-i?

(Hi, how are you)

$$
\text { سلام جطورى؟ }
$$

Kamran: sæ'la:m. qor'bunet, to che'tor-i? (qor'bunet usually used among boys in Iran which literally means the teller wishes to scarify himself for the other).

(Hi, Thanks a lot, how are you?)

Spanish:

The same situation in Spain

Carlos: Hola tio, ¿que tal?

(Hi, How are you?)

Javier: bien, todo bien. ¿Y tu?

(fine, everything is fine, and you?)

\section{CONCLUSION}

The present study shows that newcomer Iranian immigrants in Spain, based on their native language, while talking in Spanish, tend to use more polite forms, such as using titles and plural form to show their respect which in Spanish culture and language generally using title and plural form are used for elderly people or those who have higher social positions. Using polite forms by Persians in Spain can be viewed and judged from two perspectives (for Spaniards), the first one is to show the respect which usually is judged by elderlies which could be the positive side of Persian greeting in Spain, and the second one is to annoy the communicator, that means for example when university students use the title for their young professor or supervisor that is generally used for elderlies and could be count for the negative side of Persian greeting in Spain. To make the long story short, the Iranian form of politeness may annoy Spaniards and may cause a wrong impression by Spaniards. This issue in which misunderstandings in cross-cultural communication shapes is called cultural "pragmatic failure" (Thomas, 1983). Spanish politeness behavior is different from Iranian one, therefore Iranian immigrants' behavior (using the polite form) in Spain seems to be a breach of social norms. And as a result of this failure, they may not be able to have effective communication, and/or to be accepted in Spanish social gatherings, which can disrupt adaptation and acculturation of Iranian immigrants in Spain. Therefore, learning socialappropriate norms seems important for immigrants to be accepted by Spaniards and as a result of this acceptance, they might have more first-hand and continues contact which leads the immigrants to have changes in for example behavior or lifestyle, which is called acculturation (Berry, 2006; Sam, 2006; Sam \& Berry, 2006: Berry, Sam \& Rogers, 2006).

\section{REFERENCES}

[1] Almegren, R. (2018). The speech act of greeting by Saudi students of English as a foreign language. International Journal of Humanities Education. 15(4):1-22. DOI:10.18848/2327-0063/CGP/v15i04/1-22.

[2] Al-Khafaji, S. S. (2009). "Blame in English and Arabic Religious Texts: A Contrastive Study". Unpublished M.A Thesis. University of Babylon.

[3] Austin, J. L. (1962). How to do things with words. Oxford: Clarendon Press.

[4] Berry, J. W. (2006b). Context of acculturation. In D. Sam \& J. W. Berry (Eds.) Handbook of acculturation psychology (pp.2742). Cambridge University Press. https://doi.org/10.1017/CBO9780511489891.006.

[5] Berry, J. W., Sam, D., \& Rogers, A. (2006). Conclusions. In D. Sam \& J. W. Berry (Eds.), Handbook of acculturation psychology (pp.525-541). Cambridge University Press. https://doi.org/10.1017/CBO9780511489891.037.

[6] Coulthard, M. (1985). An Introduction to Discourse Analysis: Applied Linguistics and Language Study (2nd. ed.). New York: Longman.

[7] Dezhara, S. Rezaei, O. Davoudi, S. Soltani Kafrani, R. (2012). A comparative Study of Greeting Forms common among Native Male and Female Speakers of Persian. Journal of Language Teaching and Research 3.6, 1224-1232. doi:10.4304/j1tr.3.6.12241232.

[8] Elhami, A. (2020a). Communication Accommodation Theory: A Brief Review of the Literature. Journal of Advances in Education and Philosophy 4.5, 192-200.

[9] Elhami, A. (2020b). Acculturation Strategies: The Study of Bi-Dimensional and Uni-Dimensional of Filipino Immigrants in Madrid. International Journal of Social Science Research 8.2, 1-15. doi:10.5296/ijssr.v8i2.16428.

[10] Farsi, M. Zarei, L. (2013). Practical Contrastive Analysis of English and Persian with special emphasis on Relative Clauses. Time Journal of Arts and Educational Research 1.2, 7-9.

[11] Holmes, Janet and Brian, W. King. (2017). Gender and sociopragmatics. In Anne Baron, Gu Yueguo and Gerard Steen (eds.) Rutledge Handbook of Pragmatics. London: Rutledge. 121-138.

[12] Ibrahim, A. S. (1995). Sosiolinguistik, kajian, tujuan, pendekatan dan problem. Surabaya: Usaha Offset. 
[13] Krivonos, P. Knapp, M. (1975). "Initiating Communication: What Do You Say When You Say Hello? Central States Speech Journal, 26:115-25.

[14] Moradi, H. \& Chen, J. (2018). A contrastive analysis of Persian and English vowels and consonants. LEGE ARTIS, Language yesterday, today, tomorrow 3.2, 105-131. doi: 10.2478/lart-2018-0016.

[15] Sacks, Harvey. (1975). Everyone has to lie. In: Sanches, Mary and Ben Blount (eds.), Sociocultural Dimensions of Language Use. New York: Academic Press 57-79

[16] Salmani-Nodoushan, M. A. (2007). Greeting Forms in English and Persian: A Socio-Pragmatic Perspective. Pakistan Journal of Social Sciences 4, 355-362.

[17] Sam, D. (2006). Acculturation: conceptual and methods. In D. Sam \& J. W. Berry (Eds.), Handbook of acculturation psychology, 11-26. Cambridge University Press. https://doi.org/10.1017/CBO9780511489891.

[18] Sam, D. L., \& Berry, J. W. (2006). The Cambridge handbook of Acculturation Psychology. Cambridge University Press. Cambridge.

[19] Searle, J. (1977). Taxonomy of speech acts. Academic Press, New York, 89- 96.

[20] Thomas, (1983). Cross-cultural pragmatic failure. Applies Linguistics 4.2, 91-109.

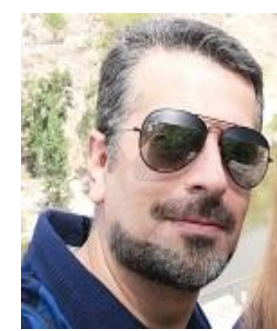

Ali Elhami (Tehran, Iran, 1982) is doing his Ph.D. in Philosophy and Language Science at the Universidad Autónoma de Madrid, Spain. His research interests are intercultural contact, language learning, language teaching, and cross-cultural studies.

He has worked for reputable language academies in Tehran, Iran for more than 10 years as an English language teacher, and published some articles related to language teaching and learning, intercultural contact and communication accommodation theory (CAT), also he has attended as a presenter in different international conferences around the world such as Indonesia, Thailand, and Italy, and was a session chair in two international conferences. 